\title{
Association of estrogen receptor beta variants and serum levels of estradiol with risk of colorectal cancer: a case control study
}

Huanlei $\mathrm{Wu}^{1+}$, $\mathrm{Li} \mathrm{Xu}^{4+}$, Jigui Chen ${ }^{3}$, Junbo Hu${ }^{2}$, Shiying $\mathrm{Yu}^{1}$, Guangyuan $\mathrm{Hu}^{1}$, Liu Huang ${ }^{1}$, Xiaoping Chen ${ }^{2^{*}}$, Xianglin Yuan ${ }^{* *}$ and Guojun Li, $i^{4,5}$

\begin{abstract}
Background: Endogenous estrogens may play a vital role in colorectal tumorigenesis. Estrogen receptor beta is the predominant subtype which mediates the biological effect of estrogens, while loss of expression of estrogen receptor beta has been indicated as a common step in the development of colorectal cancer (CRC). Epidemiological studies have revealed several functional polymorphisms of estrogen receptor beta (ESR2) for cancer risk, but relevant study in CRC is limited, particularly in men. This study aimed to investigate the association of circulating estradiol and variations of ESR2 with CRC risk in men.

Methods: We initiated a case-control study consisting of 390 patients with CRC and 445 healthy controls in men only. We genotyped ESR2 single nucleotide polymorphisms (SNPs) rs1256049 and rs4986938 and measured serum estradiol concentration using chemilluminescence immunoassay. Multivariable logistic regression model was performed to evaluate the associations between these variables and CRC risk.

Results: ESR2 rs1256049 CT/TT genotypes were associated with reduced risk of CRC (odds ratio [OR], 0.7, 95\% confidence interval [Cl], 0.5-1.0), while rs4986938 CT/TT genotypes were associated with increased risk of CRC (OR, $1.5,95 \% \mathrm{Cl}, 1.0-2.1)$. In addition, the CRC risk increased with the number of risk genotypes of these two SNPs in a dose-response manner $\left(P_{\text {trend }}, 0.003\right)$. Specifically, subjects carrying risk genotypes of both SNPs had the highest risk of $C R C(O R, 2.0,95 \% \mathrm{Cl}, 1.3-3.3$.$) . Moreover, serum estradiol concentration alone was associated with risk of CRC in$ men (OR, 1.2, 95\% Cl, 1.0-1.3). However, individuals presenting both rs4986938 CT/TT genotypes and high level of serum estradiol had a high risk of CRC (OR, 2.3, 95\% Cl, 1.4-3.9), compared with those presenting CC genotype and low level of serum estradiol. The similar joint results were not observed for SNP rs 1256049.
\end{abstract}

Conclusions: These results suggest that endogenous estrogen and genetic variations in ESR2 may individually, or more likely jointly, affect CRC risk in male Han Chinese population, while larger studies are needed to validate our findings.

Keywords: Colorectal cancer, Endogenous estrogen, Estrogen receptors, Single nucleotide polymorphisms

\footnotetext{
* Correspondence: tjchenxp@gmail.com; yxl@medmail.com.cn

${ }^{\dagger}$ Equal contributors

${ }^{1}$ Department of Oncology, Tongji Hospital, Huazhong University of Science and Technology, 1095 Jiefang Ave, Wuhan 430030, Hubei, China

${ }^{2}$ Department of Surgery, Tongji Hospital, Huazhong University of Science and

Technology, 1095 Jiefang Ave, Wuhan 430030, Hubei, China

Full list of author information is available at the end of the article
} 


\section{Background}

Colorectal cancer (CRC) is a major health problem in China and worldwide. With more than one million new cases diagnosed and more than 500,000 deaths each year, it has become the third most common cancer and the fourth most common cause of cancer death globally $[1,2]$. In addition to smoking, alcohol drinking, dietary factors and obesity, estrogens appear to play a role in CRC carcinogenesis [3-5]. Inherited predisposition may also influence CRC development [1].

While typically referred to as female hormone, estrogens regulate a board range of important functions in both females and males. Estrogen induction of cell proliferation has been considered as a critical step in carcinogenesis of gynecologic tissues including breast, endometrium and ovary, and also has been suggested to involve in cancer of colon and prostate [6]. An emerging body of evidence supports that endogenous and exogenous estrogens may play different roles in colorectal tumorigenesis[7]. For instance, the Women's Health Initiative (WHI) study observed reduced CRC rates by $37 \%$ in postmenopausal women receiving estrogen-plusprogestin formulations compared to those receiving placebos, and several studies have reported similar observations [8-12]. In contrast, two prospective studies reported that high concentrations of circulating estrogen conferred increased risk for CRC [13,14]. It is noted, however, that all the studies published used women only as the study subjects. The correlation between endogenous estrogen and the risk of CRC in men has not yet been evaluated.

The biological effects of estrogens are mediated by estrogen receptors (ER) $\alpha$ and $\beta$, which belong to the nuclear hormone receptor superfamily and act as ligandactivated transcription factors [15]. ER $\beta$ is the predominant subtype of estrogen receptor in colorectal epithelial cells; its loss of expression has been indicated as a common step in the development of CRC $[6,16-18]$. ER $\beta$ is encoded by estrogen receptor $\beta$ (ESR2) gene, which is located on chromosome 14q23.2 and covers a genomic region of $111.5 \mathrm{~kb}$ [19]. Several ESR2 genetic variants have been investigated, including rs1256049 in exon 5, which causes a synonymous change of unknown functional significance, and rs4986938, which is located in the 3 '-untranslated region of the ESR2 gene [20,21]. Both rs1256049 and rs4986938 have been associated with a number of diseases, including breast cancer, endometrial cancer, prostate cancer, reduced bone mineral density, and cardiovascular disease [22-28]. Only few studies attempted so far to evaluate the ESR2 polymorphism in cancer of colon and rectum and reported conflicting results $[25,29]$.

Given the potential roles of estrogens in CRC and the importance of ER $\beta$ in estrogen function, we hypothesized that endogenous estrogen level and ESR2 genetic variations may individually, or more likely jointly, be associated with the risk of CRC in men. We therefore conducted this male only case-control study to examine the role of functional ESR2 SNPs rs1256049 and rs4986938 and circulating concentrations of estradiol in CRC risk.

\section{Methods \\ Study population}

The present study included a total of 835 unrelated male subjects, of which 390 were patients with CRC and 445 were controls. Among patients with CRC, 168 were recruited between 2008 and 2011 from Tongji Hospital, which is affiliated with Tongji Medical College, and 222 were recruited between 2009 and 2011 from Wuhan Eighth Hospital. These two hospitals were chosen because they are the regional reference center for CRC treatment. Biopsy evaluation was performed in each case and the final diagnosis was confirmed by histopathology. The controls are healthy volunteers recruited from Tongji Hospital Physical Center during the same period who received a comprehensive health examination. The exclusion criteria for both cases and controls included 1) age less than 15 years at the time of diagnosis (cases) or recruitment (control); 2) previous history of malignancies; 3) history of inflammatory bowel disease including familial adenomatous polyposis, ulcerative colitis, and Crohn's disease; 4) history of chronic hepatic, renal and endocrine disease; 5) family history of CRC; 6) currently taking medication which was known to influence sex hormone level, and 7) diagnosed with hypertension and diabetes mellitus, which could affect sex hormone level. In addition, those who had gastrointestinal pain, detection of blood in stool, or currently diagnosed with communicable diseases such as tuberculosis and acquired immune deficiency syndrome were excluded from the control group. The cases and controls were from the same geographic region and limited to Han Chinese ethnicity.

Eligible participants were interviewed in person to collect demographic and exposure information including smoking and alcohol drinking status (response rate 98\%). Participants who have smoked more than 100 cigarettes in their lifetimes were classified as eversmokers; the others were classified as never-smokers. Participants who have drunk alcohol beverage at least once a week for more than one year were classified as ever-drinkers; the others were classified as neverdrinkers.

The study conformed to guidelines set forth by the Declaration of Helsinki and was approved by the ethics committee of the Tongji Medical College. Written informed consent was obtained from each participant before recruitment. 


\section{Genotyping}

Peripheral blood samples were collected from all participants. Genomic DNA was extracted from peripheral blood using a FUJI whole blood DNA kit (Fujifilm Corporation, Japan). All participants were genotyped for rs1256049 and rs4986938 polymorphisms using a Taqman SNP genotyping assay implemented by the ABI Prism 7900HT Sequence Detection System (Applied Biosystems). Primer and probe sequences were optimized using the SNP assay design service provided by Applied Biosystems. For each SNP, the call rate was more than $98 \%$. To verify the accuracy of Taqman genotyping results, $5 \%$ of the samples were randomly selected and genotyped using the direct-sequencing method with a concordance of no less than $99 \%$.

\section{Analysis of serum estrogen concentration}

Endogenous estrogens are a group of steroidal compounds including 17b-estradiol, estrone, and estriol. Because the bioactivity of $17 \mathrm{~b}$-estradiol is the greatest of the three in vivo [30], we chose to evaluate estradiol concentration in serum. Estradiol concentrations were measured using blood samples collected at the initial visit. The blood samples were centrifuged at $1300 \mathrm{~g}$ for 10 minutes, and the separated sera were stored at $-70{ }^{\circ} \mathrm{C}$ within 2 hours of blood collection.

Because some samples did not have enough serum for measurement, estradiol concentrations were available from 359 male patients and 378 male controls. The detection rate was $99 \%$. Participants having no estradiol data were not significantly different from participants having estradiol data in regard to age, gender, smoking, or drinking status (data not shown). Using $300 \mu \mathrm{l}$ of available serum, estradiol concentrations (in pictograms per milliliter) were quantified using sensitive in vitro estradiol diagnostic kits (the normal male adult reference value is $20-75 \mathrm{pg} / \mathrm{ml}$ ) (chemiluminescence immunoassay, Beckman Coulter Inc., USA). Laboratory personnel were blinded to case status. The samples were analyzed in random order, and approximately $5 \%$ of the samples were repeated with a $100 \%$ concordance.

\section{Statistical analysis}

The distributions of demographic and exposure characteristics among the cases and controls were compared with Pearson chi-square test. For each ESR2 SNP, deviation from Hardy-Weinberg equilibrium was assessed by chi-square test in controls. Multivariable logistic regression model, with adjustment for potential confounding factors, was used to calculate odds ratios (ORs) and 95\% confidence intervals (CIs) for genotype-specific cancer risk. In addition, we conducted subgroup analyses stratified by age, smoking status and alcohol drinking status to examine the genotype-specific cancer risk in each subgroup. Cut-off of age was based on the median age among controls. The significance of the interactions was determined by a likelihood ratio test comparing a full model including the interaction term with the main effect model.

The levels of estradiol in male cases and male controls were compared using multivariable logistic regression model adjusted for age. A square-root transformation was applied to the estradiol concentration. We also assessed the joint association of estradiol level and ESR2 rs1256049 and rs4986938 genotypes with CRC risk by multivariable logistic regression model. For serum estradiol, the mean estradiol level in all male subjects (including cases and controls) was used as the grouping standard: higher than average concentration was defined as high estradiol level and lower than or equal to average concentration was defined as low estradiol level.

All statistical tests were 2 -sided, and a $P$ value less than 0.05 was considered to be statistically significant. All analyses were performed using SAS software, version 9.2 (SAS Institute Inc., Cary, NC, USA).

\section{Results}

\section{Characteristics of participants}

Table 1 depicts distributions of selected characteristics of male only patients with CRC and controls. Cases were older, more likely to be never-smokers and neverdrinkers than controls in this study. The average age (standard deviation [SD]) at diagnosis of CRC was 58.3 (13.3) years (median, 58 years) in these patients. The average age (SD) at recruitment was 50.0 (9.4) years (median, 48 years) in the healthy controls.

\section{Genotype specific risk association analyses}

Two ESR2 SNPs, rs1256049 and rs4986938, were genotyped. Among controls, genotype distributions were in

Table 1 Selected demographic characteristics of colorectal cancer cases and controls

\begin{tabular}{|c|c|c|c|c|c|}
\hline \multirow[b]{2}{*}{ Characteristics } & \multicolumn{2}{|c|}{ Controls $(n=445)$} & \multicolumn{2}{|c|}{ Cases $(n=390)$} & \multirow[b]{2}{*}{$P$-value } \\
\hline & $n$ & $\%$ & $n$ & $\%$ & \\
\hline \multicolumn{6}{|l|}{ Age, years } \\
\hline$\leq 48$ & 239 & 53.7 & 82 & 21.0 & $<0.001$ \\
\hline$>48$ & 206 & 46.3 & 308 & 79.0 & \\
\hline \multicolumn{6}{|l|}{ Smoking status } \\
\hline Ever & 283 & 63.6 & 181 & 46.4 & $<0.001$ \\
\hline Never & 162 & 36.4 & 209 & 53.6 & \\
\hline \multicolumn{6}{|c|}{ Alcohol drinking Status } \\
\hline Ever & 292 & 65.6 & 137 & 39.0 & $<0.001$ \\
\hline Never & 153 & 34.4 & 214 & 61.0 & \\
\hline
\end{tabular}

${ }^{\mathrm{a}} P$ values were calculated from chi-square test. 
Table 2 ESR2 genotype frequencies in colorectal cancer cases and controls and odds ratio estimates

\begin{tabular}{|c|c|c|c|c|c|c|}
\hline \multirow[b]{2}{*}{ Genotypes } & \multicolumn{2}{|c|}{$\begin{array}{l}\text { Controls }^{a} \\
(n=445)\end{array}$} & \multicolumn{2}{|c|}{$\begin{array}{l}\text { Cases } \\
(n=390)\end{array}$} & \multirow[b]{2}{*}{$\mathrm{OR}^{\mathrm{b}}(95 \% \mathrm{Cl})$} & \multirow[b]{2}{*}{$P$-value ${ }^{\mathrm{k}}$} \\
\hline & $\bar{n}$ & $\%$ & $\mathrm{n}$ & $\%$ & & \\
\hline \multicolumn{7}{|l|}{ rs1256049 } \\
\hline CC (Ref. $\left.{ }^{\complement}\right)$ & 167 & 37.9 & 168 & 43.9 & 1.0 & 0.029 \\
\hline $\mathrm{CT} / \mathrm{TT}$ & 274 & 62.1 & 215 & 56.1 & $0.7(0.5-1.0)$ & \\
\hline \multicolumn{7}{|l|}{ rs4986938 } \\
\hline CC (Ref. $\left.{ }^{C}\right)$ & 349 & 79.9 & 277 & 71.8 & 1.0 & 0.036 \\
\hline $\mathrm{CT} / \mathrm{TT}$ & 88 & 20.1 & 109 & 28.2 & $1.5(1.0-2.1)$ & \\
\hline \multicolumn{7}{|c|}{ rs1256049 + rs4986938 } \\
\hline $\begin{array}{l}0 \text { risk genotype } \\
\text { (Ref.') }\end{array}$ & 232 & 53.2 & 165 & 43.4 & 1.0 & 0.014 \\
\hline 1 risk genotype & 156 & 35.8 & 154 & 40.5 & $1.3(0.9-1.8)$ & \\
\hline \multirow[t]{2}{*}{2 risk genotypes } & 48 & 11.0 & 61 & 16.1 & $2.0(1.3-3.3)$ & \\
\hline & & & & & $P_{\text {trend }}=$ & 0.003 \\
\hline $\begin{array}{l}\text { No risk genotype } \\
\text { (Ref.') }\end{array}$ & 232 & 53.2 & 165 & 43.4 & 1.0 & 0.016 \\
\hline With risk genotype & 204 & 46.8 & 215 & 56.6 & $1.5(1.1-2.0)$ & \\
\hline
\end{tabular}

${ }^{a}$ The genotype frequencies in controls were in Hardy-Weinberg equilibrium ( $P=0.686$ for rs 1256049 and $P=0.669$ for rs 4986938 , Chi-square test). ${ }^{\mathrm{b}} \mathrm{ORs}$ and $P$ values were calculated using unconditional logistic regression model adjusted for age, smoking status and alcohol drinking status. ${ }^{\mathrm{C}}$ Ref. $=$ reference group.

Hardy-Weinberg equilibrium ( $P=0.686$ for rs1256049 and $P=0.669$ for rs4986938).

Table 2 shows the genotype specific risks of CRC in the studied population: compared to the homozygous
CC genotype, CT/TT genotypes of rs1256049 and rs4986938 were associated with significant reduced and increased risk of CRC, respectively. Similarly, under logadditive model, risk estimates were 0.8 (95\% CI, 0.6-1.0) for rs1256049 and 1.5 (95\% CI, 1.0-2.0) for rs4986938. No significant association was found for codominant model (data not shown).

In order to assess the joint effect of these polymorphisms on CRC risk in men, we categorized all subjects into 3 groups based on the number of risk genotypes which were determined on the basis of the risk estimates in Table 2. The risk genotypes were rs1256049 CC genotype and rs4986938 CT/TT genotypes. We also dichotomized patients into groups with and without risk genotype. As shown in Table 2, subjects with risk genotype had a significantly increased risk of CRC compared with those carrying no risk genotype (OR, 1.5, 95\% CI, 1.1-2.0). Specifically, subjects carrying risk genotype of both polymorphisms had the highest risk of developing CRC (OR, 2.0, 95\% CI, 1.3-3.3). We also found the CRC risk in men increased with the number of risk genotype in a dose-response manner $\left(P_{\text {trend }}, 0.003\right)$. Additionally, we evaluated the combined effect of risk alleles of rs1256049 and rs4986938 and found increased risk for CRC associated with cumulative number of risk alleles (OR, 1.3, 95\% CI, 1.1-1.6, P, 0.003).

\section{Stratification analysis}

The genotype specific risks of CRC stratified by age, smoking and alcohol drinking status are shown in Table 3. The protective effect of rs1256049 CT/TT

Table 3 Stratification analysis of colorectal cancer risk associated with ESR2 genotypes

\begin{tabular}{|c|c|c|c|c|c|c|}
\hline \multirow[b]{3}{*}{ Subgroups } & \multicolumn{2}{|l|}{ rs1256049 } & \multirow[b]{3}{*}{$\mathrm{OR}^{c}(95 \% \mathrm{Cl})$} & \multicolumn{2}{|l|}{ rs4986938 } & \multirow[b]{3}{*}{$\mathrm{OR}^{\mathrm{c}}(95 \% \mathrm{Cl})$} \\
\hline & $\overline{C C}$ (Ref. ${ }^{a}$ ) & $\mathrm{CT} / \mathrm{TT}$ & & $\overline{C C}$ (Ref. ${ }^{a}$ ) & $\mathrm{CT} / \mathrm{TT}$ & \\
\hline & $\mathrm{Ca} / \mathrm{Co}^{b}$ & $\overline{\mathrm{Ca} / \mathrm{Co}^{\mathrm{b}}}$ & & $\overline{\mathrm{Ca} / \mathrm{Co}^{\mathrm{b}}}$ & $\mathrm{Ca} / \mathrm{Co}^{\mathrm{b}}$ & \\
\hline \multicolumn{7}{|l|}{ Age, years } \\
\hline$\leq 48$ & $30 / 88$ & $50 / 150$ & $1.0(0.5-1.8)$ & $55 / 186$ & $27 / 49$ & $1.4(0.7-2.7)$ \\
\hline$>48$ & $138 / 79$ & $165 / 124$ & $0.7(0.5-1.0)$ & $222 / 163$ & $82 / 39$ & $1.5(0.9-2.3)$ \\
\hline$P_{\text {interaction }}$ & & & 0.483 & & & 0.831 \\
\hline \multicolumn{7}{|c|}{ Smoking status } \\
\hline Ever & $88 / 104$ & $87 / 175$ & $0.5(0.4-0.8)$ & $139 / 226$ & $40 / 53$ & $1.0(0.6-1.7)$ \\
\hline Never & $80 / 63$ & $128 / 162$ & $1.0(0.6-1.6)$ & $138 / 123$ & $69 / 35$ & $2.2(1.3-4.0)$ \\
\hline$P_{\text {interaction }}$ & & & 0.061 & & & 0.058 \\
\hline \multicolumn{7}{|c|}{ Alcohol drinking status } \\
\hline Ever & $66 / 112$ & $66 / 178$ & $0.6(0.4-1.0)$ & $100 / 229$ & $34 / 57$ & $1.6(0.9-2.7)$ \\
\hline Never & $89 / 123$ & $55 / 96$ & $0.8(0.5-1.2)$ & $148 / 120$ & $66 / 31$ & $1.5(0.9-2.4)$ \\
\hline$P_{\text {interaction }}$ & & & 0.473 & & & 0.651 \\
\hline
\end{tabular}

${ }^{\mathrm{a}}$ Ref. = reference group.

${ }^{\mathrm{b}} \mathrm{Ca} / \mathrm{Co}=$ colorectal cancer cases/controls.

${ }^{\mathrm{c} O R s}$ were calculated using unconditional logistic regression model adjusted for age, smoking status and alcohol drinking status. 


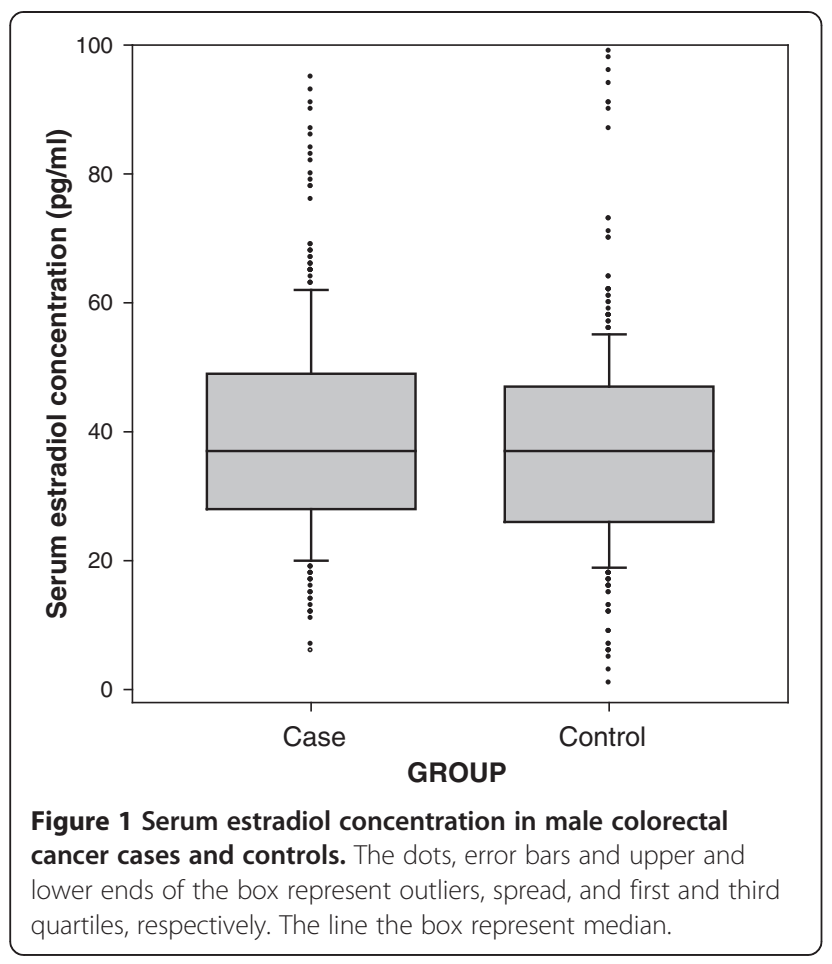

genotypes on CRC was likely confined to old subjects, ever-smokers and ever-drinkers: rs1256049 CT/TT genotypes were associated with significantly reduced risk of CRC in $>48$ years old subjects (OR, 0.7, 95\% CI, 0.5$1.0, P, 0.047$ ), in ever-smokers (OR, 0.5, 95\% CI, 0.4-0.8, $P, 0.005$ ), and in ever-drinkers (OR, 0.6, 95\% CI, 0.4-1.0, $P, 0.038)$, after adjustment for potential confounding factors, while no significant interaction was found with age, smoking status and alcohol drinking status. For rs4986938, the ORs for CT/TT genotypes compared to $\mathrm{CC}$ genotype were significant for never-smokers only (OR, 2.2, 95\% CI, 1.3-4.0, P, 0.005).
Serum estradiol concentrations in male patients with CRC and controls

As illustrated in Figure 1, we observed higher levels of serum estradiol in cases than in controls. Mean (SD) estradiol concentrations were $39.55(16.25) \mathrm{pg} / \mathrm{ml}$ in male patients with CRC and 37.45 (15.86) pg/ml in male controls. Serum estradiol levels were significantly associated with increased risk of CRC in men after adjustment for age; the adjusted OR for serum estradiol levels (continuous) was 1.2 (95\% CI, 1.0-1.3, P, 0.009).

\section{Joint association of estradiol level and ESR2 genotypes with the risk of CRC}

In Table 4, we combined the estradiol levels and ESR2 genotypes to estimate their joint effect on risk of male CRC using two models, one adjusted only for age, and another adjusted for potential risk factors of CRC including age, smoking and alcohol drinking status. Using the group of individuals with rs4986938 CC genotype and low level $(\leq 38.47 \mathrm{pg} / \mathrm{ml})$ of estradiol as reference group, the group of individuals with $\mathrm{CT} / \mathrm{TT}$ genotypes and high level $(>38.47 \mathrm{pg} / \mathrm{ml})$ of estradiol had the highest OR of 2.3 (95\% CI, 1.4-3.9) after adjusted for age among all subgroups. Such an association was weakened but remained in the same direction after further adjustment with other factors including smoking and alcohol drinking status (OR, 1.6, 95\% CI, 0.9-2.9). However, the associations of such combined serum estradiol and ESR2 genotypes with CRC risk were almost similar among those subgroups for rs1256049.

\section{Discussion}

To the best of our knowledge, the present study is the first to explore the potential role of endogenous estrogen on risk of CRC in men. We found serum estradiol level to be positively associated with increased risk of CRC in

Table 4 Joint effect of serum estradiol level and ESR2 genotypes on colorectal cancer risk in men

\begin{tabular}{|c|c|c|c|c|c|c|c|}
\hline \multirow[b]{2}{*}{ Variables } & & \multicolumn{2}{|c|}{ Controls $(n=378)$} & \multicolumn{2}{|c|}{ Cases $(n=359)$} & \multirow[b]{2}{*}{$\mathrm{OR}^{\mathrm{a}}(95 \% \mathrm{Cl})$} & \multirow[b]{2}{*}{$\mathrm{OR}^{\mathrm{b}}(95 \% \mathrm{Cl})$} \\
\hline & & $\mathbf{n}$ & $\%$ & $\mathbf{n}$ & $\%$ & & \\
\hline \multicolumn{8}{|c|}{ Estradiol + rs1256049 } \\
\hline \multirow[t]{2}{*}{ Low } & $\mathrm{CT} / \mathrm{TT}$ & 127 & 33.8 & 96 & 27.3 & 1.0 & 1.0 \\
\hline & CC & 80 & 21.3 & 87 & 24.7 & $1.6(1.0-2.4)$ & $1.7(1.1-2.6)$ \\
\hline \multirow[t]{2}{*}{ High } & $\mathrm{CT} / \mathrm{TT}$ & 109 & 29.0 & 101 & 28.7 & $1.5(1.0-2.3)$ & $1.2(0.8-1.9)$ \\
\hline & $\mathrm{CC}$ & 60 & 16.0 & 68 & 19.3 & $1.6(1.0-2.5)$ & $1.4(0.8-2.3)$ \\
\hline \multicolumn{8}{|c|}{ Estradiol + rs4986938 } \\
\hline \multirow[t]{2}{*}{ Low } & CC & 162 & 43.4 & 144 & 40.6 & 1.0 & 1.0 \\
\hline & $\mathrm{CT} / \mathrm{TT}$ & 42 & 11.3 & 43 & 12.1 & $1.1(0.7-1.9)$ & $1.1(0.6-1.9)$ \\
\hline \multirow[t]{2}{*}{ High } & CC & 136 & 36.5 & 113 & 31.8 & $1.0(0.7-1.4)$ & $0.8(0.6-1.2)$ \\
\hline & $\mathrm{CT} / \mathrm{TT}$ & 33 & 8.9 & 55 & 15.5 & $2.3(1.4-3.9)$ & $1.6(0.9-2.9)$ \\
\hline
\end{tabular}

${ }^{\mathrm{a}}$ ORs were calculated using unconditional logistic regression model adjusted for age.

${ }^{\mathrm{b}}$ ORs were calculated using unconditional logistic regression model adjusted for age, smoking status and alcohol drinking status. 
men. Our study is also the first to evaluate the relationship between ESR2 rs1256049 and rs4986938 and risk of CRC in Han Chinese and found both SNPs were associated with susceptibility to CRC in men. We observed a significant association between the risk genotypes of these two SNPs in combination and CRC risk, which was statistically significant in a dose-response manner. In addition, men possessing the risk genotypes of rs4986938 and high level of serum estradiol had significant increased risk for developing CRC.

The role of estrogens in CRC risk remains controversial. In the WHI trial, postmenopausal women who randomly assigned to combination of estrogen plus progestin therapy group were at reduced risk for CRC compared to those assigned to placebo group, the reduction (37\%) was nominally significant [12]. An early meta-analysis also reported a $20 \%$ reduction in risk of colon cancer and 19\% reduction in risk of rectal cancer associated with postmenopausal hormone therapy, and particularly current hormone use $(34 \%$ reduction of CRC risk) [10]. These observations strongly supported an inverse association between exogenous postmenopausal estrogens and CRC risk. However, endogenous estrogens may have an opposite effect on CRC risk. In the nested CRC case-control study from the WHI cohort, circulating estradiol concentration was positively associated with increased risk of CRC [13]. Similarly, the New York University Women's Health study reported a 1.8-fold increase of CRC risk in the postmenopausal women having the highest quartile of circulating estrone level compared with those having lowest quartile [14]. Although the exact mechanisms are unclear, several observations may help explain the disparate results. First, in the WHI clinical trial, estrogen plus progestin exerted a protective role, whereas oral estrogen alone achieved no such effect [31]. Second, the use of oral estrogens usually couples with increased expression of sex-hormone-binding globulin, which leads to reduced concentrations of bioavailable estrogen [32]. Finally, oral estrogens showed a negative correlation with the synthesis and activity of insulin-like growth factor I axis components, which have a protective role against CRC tumorigenesis [13]. In our study, in agreement with these previous results, we found that high circulating estradiol concentrations were associated with increased risk of CRC in men, supporting the risk effect of endogenous estrogens on CRC development. Further studies to evaluate the sex-difference and dose-difference effect of endogenous estrogens on CRC tumorigensis are warranted.

One of the most intriguing findings in our study was the joint effect of ESR2 rs4986938 genotype and estradiol levels on CRC risk. Although there was no significant interaction between rs4986938 genotypes and serum estradiol levels for CRC risk in our study (data not shown), the joint effect was likely close to the expected additive scale, that is, individuals with both high estradiol level and rs4986938 risk genotypes had a significant OR of 2.3, compared with individuals with low estradiol level and wild-type genotype, which was higher than the sum of ORs in those with high estradiol level only (OR, 1.1) and in those with wild-type genotype alone (OR, 1.0). This result supports the possible influence of interaction between ESR2 gene and endogenous estrogens on the risk of CRC. It is noteworthy that the biological action of estrogens has to be through its receptors, and colon tissue is characterized by a predominance of $E R \beta$, the protein encoded by ESR2 [16]. Although the mechanisms remain largely unknown, frequent loss of ESR2 expression in CRC tissue has been observed, suggesting involvement of ER $\beta$ in development and progression of CRC $[17,18,33]$. Moreover, some ESR2 variants have been shown to alter the function of the receptor, affecting the tissue's response to estrogens [34]. There is also evidence that rs4986938 could affect RNA stability of the ESR2 gene [35,36]. Our findings of the joint effect of rs4986938 and estradiol levels on CRC risk and the significant associations between ESR2 SNPs and CRC risk provides supporting evidence of functional potential of ESR2 gene in estrogen-related CRC tumorigenesis, while in vivo and in vitro research as well as evaluation in larger population are required for further elucidation.

ESR2 rs1256049 CT/TT genotypes conferred a reduced risk of CRC in this Han Chinese case-control population. This is in agreement with the study of Slattery et al. which evaluated ESR2 rs1256049 in a casecontrol population of vast majority of Caucasian and found that the $\mathrm{C}$ allele of rs1256049 conferred an increased risk of rectal cancer among the total population if diagnosed before 60 years of age, and an increased risk in colon cancer if estrogen positive [25]. A study in Japanese population, however, found an increased risk of CRC linked with rs1256049 TT genotype [29]. The ethnic difference may lead to the discrepancy among these studies. More large-scale studies in different ethnic background population are warrant to validate the potential role of ESR2 rs1256049 in susceptibility to CRC.

There are certain limitations to our findings. First, because all patients enrolled in this study were ethnic Han Chinese, our ability to adequately assess risk in other ethnic populations is limited. Further studies using sufficient numbers of subjects from other races and ethnic groups are needed to extend and confirm our findings. Second, only a limited number of candidate SNPs were selected in this study, which is not fully representative of the complexity of genes in the estrogen receptor pathway. Finally, due to the nature of hospital-based casecontrol study design, a potential selection bias should be 
taken into consideration when interpreting the results. One of the reasons for the difference between cases and controls in smoking status could be the selection bias. Additionally, using hospital-based controls could generate Berkson bias which might influence the frequencies of ESR2 genotypes and the susceptibility to CRC risk. However, the genotype frequencies in the controls did not deviate significantly from the Hardy-Weinberg equilibrium, thus, the selection bias may have been minimized in this study.

\section{Conclusions}

Our findings may support a role for estrogens in colorectal tumorigenesis. We found that both serum estradiol and ESR2 genetic variants individually were associated with risk of CRC. In addition, individuals with both rs4986938 risk genotypes and high estradiol level had a higher risk for developing CRC in men. Therefore, the functional SNPs, hormone environmental factors, and their interactions, may provide a new clue for individualized evaluation CRC and offer effective prevention strategies in the future. However, our findings need to be validated by larger studies, and additional functional investigations of mechanisms are warranted.

\section{Abbreviations \\ Cl: Confidence interval; CRC: Colorectal cancer; ER: Estrogen receptor; ESR2: Estrogen receptor $\beta$ gene; OR: Odds ratio; SD: Standard deviation; SNP: Single nucleotide polymorphism; WHI: Women's Health Initiative.}

\section{Competing interests}

The authors declare that they have no competing interests.

\section{Authors' contributions}

HW collected the data, performed the experiment and drafted the manuscript. LX performed data analysis and drifted the manuscript. JC, JB, SY, GH, and LH participated in patients' recruitment, study materials collection and experiment design. XC, XY and GL participated in the design of the study, interpretation of data and revision of the manuscript. All authors read and approved the final manuscript.

\section{Acknowledgements}

This work was supported by Grant No.81071832 from National Natura Science Foundation of China and Grant No.JX5A01 from the Key Fund Project of Hubei Provincial Department of Health (X.L.Y.). L.X. is a postdoctoral fellow supported by Halliburton Employees Fellow in Cancer Prevention funds (Shine Chang, Principal Investigator).We thank Fan Wang, Juan Cai, Jia Hu and Lihong Zhang for helpful discussion and technical support.

\section{Author details \\ 'Department of Oncology, Tongji Hospital, Huazhong University of Science and Technology, 1095 Jiefang Ave, Wuhan 430030, Hubei, China. ${ }^{2}$ Department of Surgery, Tongji Hospital, Huazhong University of Science and Technology, 1095 Jiefang Ave, Wuhan 430030, Hubei, China. ${ }^{3}$ Department of Surgery, Wuhan 8th Hospital, Wuhan, People's Republic of China. ${ }^{4}$ Department of Head and Neck Surgery, The University of Texas MD Anderson Cancer Center, Houston, TX, USA. ${ }^{5}$ Department of Epidemiology, The University of Texas MD Anderson Cancer Center, Houston, TX, USA.}

\section{References}

1. Jemal A, Siegel R, Xu J, Ward E: Cancer statistics, 2010. CA Cancer J Clin 2010, 60:277-300.

2. Yang L, Parkin DM, Li LD, Chen YD, Bray F: Estimation and projection of the national profile of cancer mortality in China: 1991-2005. Br J Cancer 2004, 90:2157-2166.

3. Hendifar A, Yang D, Lenz F, Lurje G, Pohl A, Lenz C, Ning Y, Zhang W, Lenz $\mathrm{HJ}$ : Gender disparities in metastatic colorectal cancer survival. Clin Cancer Res 2009, 15:6391-6397.

4. McMichael AJ, Potter JD: Reproduction, endogenous and exogenous sex hormones, and colon cancer: a review and hypothesis. J Natl Cancer Inst 1980, 65:1201-1207.

5. Dos Santos Silva I, Swerdlow AJ: Sex differences in time trends of colorectal cancer in England and Wales: the possible effect of female hormonal factors. Br J Cancer 1996, 73:692-697.

6. Bardin A, Boulle N, Lazennec G, Vignon F, Pujol P: Loss of ERbeta expression as a common step in estrogen-dependent tumor progression. Endocr Relat Cancer 2004, 11:537-551.

7. Zervoudakis A, Strickler HD, Park Y, Xue X, Hollenbeck A, Schatzkin A, Gunter MJ: Reproductive history and risk of colorectal cancer in postmenopausal women. J Natl Cancer Inst 2011, 103:826-834.

8. Chlebowski RT, Wactawski-Wende J, Ritenbaugh C, Hubbell FA, Ascensao J, Rodabough RJ, Rosenberg CA, Taylor VM, Harris R, Chen C, Adams-Campbell $\mathrm{LL}$, White E: Estrogen plus progestin and colorectal cancer in postmenopausal women. N Engl J Med 2004, 350:991-1004.

9. Calle EE, Miracle-McMahill HL, Thun MJ, Heath CW Jr: Estrogen replacement therapy and risk of fatal colon cancer in a prospective cohort of postmenopausal women. J Natl Cancer Inst 1995, 87:517-523.

10. Grodstein F, Newcomb PA, Stampfer MJ: Postmenopausal hormone therapy and the risk of colorectal cancer: a review and meta-analysis. Am J Med 1999, 106:574-582.

11. Newcomb PA, Storer BE: Postmenopausal hormone use and risk of largebowel cancer. J Natl Cancer Inst 1995, 87:1067-1071.

12. Rossouw JE, Anderson GL, Prentice RL, LaCroix AZ, Kooperberg C, Stefanick ML, Jackson RD, Beresford SA, Howard BV, Johnson KC, Kotchen JM, Ockene $\mathrm{J}$ : Risks and benefits of estrogen plus progestin in healthy postmenopausal women: principal results From the Women's Health Initiative randomized controlled trial. JAMA 2002, 288:321-333.

13. Gunter MJ, Hoover DR, Yu H, Wassertheil-Smoller S, Rohan TE, Manson JE, Howard BV, Wylie-Rosett J, Anderson GL, Ho GY, Kaplan RC, Li J, Xue X, Harris TG, Burk RD, Strickler HD: Insulin, insulin-like growth factor-I, endogenous estradiol, and risk of colorectal cancer in postmenopausal women. Cancer Res 2008, 68:329-337.

14. Clendenen TV, Koenig KL, Shore RE, Levitz M, Arslan AA, Zeleniuch-Jacquotte A: Postmenopausal levels of endogenous sex hormones and risk of colorectal cancer. Cancer Epidemiol Biomarkers Prev 2009, 18:275-281.

15. Parker MG, Arbuckle N, Dauvois S, Danielian P, White R: Structure and function of the estrogen receptor. Ann N Y Acad Sci 1993, 684:119-126.

16. Fiorelli G, Picariello L, Martineti V, Tonelli F, Brandi ML: Functional estrogen receptor beta in colon cancer cells. Biochem Biophys Res Commun 1999, 261:521-527.

17. Barone M, Tanzi S, Lofano K, Scavo MP, Guido R, Demarinis L, Principi MB, Bucci A, Di Leo A: Estrogens, phytoestrogens and colorectal neoproliferative lesions. Genes Nutr 2008, 3:7-13.

18. Kennelly R, Kavanagh DO, Hogan AM, Winter DC: Oestrogen and the colon: potential mechanisms for cancer prevention. Lancet Oncol 2008, 9:385-391.

19. Enmark E, Pelto-Huikko M, Grandien K, Lagercrantz S, Lagercrantz J, Fried G, Nordenskjold M, Gustafsson JA: Human estrogen receptor beta-gene structure, chromosomal localization, and expression pattern. J Clin Endocrinol Metab 1997, 82:4258-4265.

20. Silvestri S, Thomsen AB, Gozzini A, Bagger Y, Christiansen C, Brandi ML: Estrogen receptor alpha and beta polymorphisms: is there an association with bone mineral density, plasma lipids, and response to postmenopausal hormone therapy? Menopause 2006, 13:451-461.

21. Kim JJ, Choi YM, Choung SH, Yoon SH, Lee GH, Moon SY: Estrogen receptor beta gene $+1730 \mathrm{G} / \mathrm{A}$ polymorphism in women with polycystic ovary syndrome. Fertil Steril 2010, 93:1942-1947.

22. Hernandez J, Balic I, Johnson-Pais TL, Higgins BA, Torkko KC, Thompson IM, Leach RJ: Association between an estrogen receptor alpha gene 
polymorphism and the risk of prostate cancer in black men. J Urol 2006, 175:523-527.

23. Shearman AM, Cupples LA, Demissie S, Peter I, Schmid CH, Karas RH, Mendelsohn ME, Housman DE, Levy D: Association between estrogen receptor alpha gene variation and cardiovascular disease. JAMA 2003, 290:2263-2270.

24. van Meurs JB, Schuit SC, Weel AE, van der Klift M, Bergink AP, Arp PP, Colin EM, Fang Y, Hofman A, van Duijn CM, van Leeuwen JP, Pols HA, Uitterlinden AG: Association of 5 ' estrogen receptor alpha gene polymorphisms with bone mineral density, vertebral bone area and fracture risk. Hum Mol Genet 2003, 12:1745-1754.

25. Slattery ML, Sweeney C, Murtaugh M, Ma KN, Wolff RK, Potter JD, Caan BJ, Samowitz W: Associations between ERalpha, ERbeta, and AR genotypes and colon and rectal cancer. Cancer Epidemiol Biomarkers Prev 2005, 14:2936-2942.

26. Weiderpass E, Persson I, Melhus H, Wedren S, Kindmark A, Baron JA: Estrogen receptor alpha gene polymorphisms and endometrial cancer risk. Carcinogenesis 2000, 21:623-627.

27. Schuit SC, Oei HH, Witteman JC, van Kessel CH Geurts, van Meurs JB, Nijhuis RL, van Leeuwen JP, de Jong FH, Zillikens MC, Hofman A, Pols HA, Uitterlinden AG: Estrogen receptor alpha gene polymorphisms and risk of myocardial infarction. JAMA 2004, 291:2969-2977.

28. Shen Y, Li DK, WU J, Zhang Z, Gao E: Joint effects of the CYP1A1 Mspl, ERalpha Pvull, and ERalpha Xbal polymorphisms on the risk of breast cancer: results from a population-based case-control study in Shanghai, China. Cancer Epidemiol Biomarkers Prev 2006, 15:342-347.

29. Ikeda S, Sasazuki S, Natsukawa S, Shaura K, Koizumi Y, Kasuga Y, Ohnami S, Sakamoto H, Yoshida T, Iwasaki M, Tsugane S: Screening of 214 single nucleotide polymorphisms in 44 candidate cancer susceptibility genes: a case-control study on gastric and colorectal cancers in the Japanese population. Am J Gastroenterol 2008, 103:1476-1487.

30. Dubey RK, Jackson EK: Cardiovascular protective effects of 17betaestradiol metabolites. J Appl Physiol 2001, 91:1868-1883.

31. Ritenbaugh C, Stanford JL, Wu L, Shikany JM, Schoen RE, Stefanick ML, Taylor V, Garland C, Frank G, Lane D, Mason E, McNeeley SG, Ascensao J, Chlebowski RT: Conjugated equine estrogens and colorectal cancer incidence and survival: the Women's Health Initiative randomized clinical trial. Cancer Epidemiol Biomarkers Prev 2008, 17:2609-2618.

32. Raudaskoski T, Laatikainen T, Kauppila A: Sex-hormone binding globulin as an indicator of the hepatic impacts of continuous combined hormone replacement regimens. Maturitas 1998, 29:87-92.

33. Foley EF, Jazaeri AA, Shupnik MA, Jazaeri O, Rice LW: Selective loss of estrogen receptor beta in malignant human colon. Cancer Res 2000, 60:245-248.

34. Hall JM, Couse JF, Korach KS: The multifaceted mechanisms of estradiol and estrogen receptor signaling. J Biol Chem 2001, 276:36869-36872.

35. Maguire P, Margolin S, Skoglund J, Sun XF, Gustafsson JA, Borresen-Dale AL, Lindblom A: Estrogen receptor beta (ESR2) polymorphisms in familial and sporadic breast cancer. Breast Cancer Res Treat 2005, 94:145-152.

36. Sowers MR, Jannausch ML, McConnell DS, Kardia SR, Randolph JF Jr: Endogenous estradiol and its association with estrogen receptor gene polymorphisms. Am J Med 2006, 119:S16-S22.

doi:10.1186/1471-2407-12-276

Cite this article as: Wu et al: Association of estrogen receptor beta variants and serum levels of estradiol with risk of colorectal cancer: a case control study. BMC Cancer 2012 12:276.

\section{Submit your next manuscript to BioMed Central and take full advantage of:}

- Convenient online submission

- Thorough peer review

- No space constraints or color figure charges

- Immediate publication on acceptance

- Inclusion in PubMed, CAS, Scopus and Google Scholar

- Research which is freely available for redistribution 